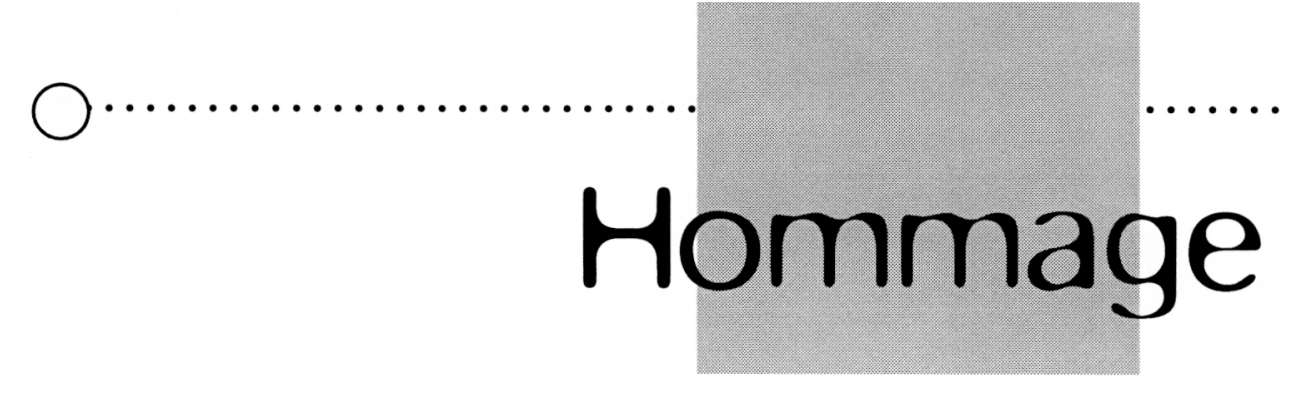

\title{
Joseph Gabel (1912-2004)
}

Joseph Gabel est mort le 15 juin 2004, à la suite d'une longue maladie. Il allait avoir 92 ans.

Né en 1912 à Budapest, il quitta la Hongrie à 19 ans, en raison du numerus clausus imposé aux Juifs, pour étudier la médecine en France.

Il passa sa thèse en 1939 sur « Le génie et la folie dans l'œuvre de Maupassant ".

C'est à Toulouse qu'il vécut dans la clandestinité pendant une partie de la guerre, il enseignait muni de faux papiers. Puis il se réfugia en Espagne, dont la langue s'ajouta au nombre déjà considérable de celles qu'il parlait de manière pratiquement parfaite. Après la guerre, faisant fonction d'interne, il poursuivit à Paris sa formation en psychiatrie ; il était très influencé par Minkowski.

Il bifurqua ensuite vers la sociologie, s'attachant à appliquer à celle-ci les concepts de conscience morbide et de dédialectisation, qu'il tirait de la psychopathologie de la schizophrénie, et développant celui de "Fausse conscience ", ainsi que se nommaient sa thèse et le livre, publié en 1962, qui, traduit en de nombreuses langues, l'a fait connaitre dans le monde entier.

De 1965 à 1971, il enseigna à l'Université de Rabat, puis à Amiens, à l'Université de Picardie, dont il fut Professeur Émérite après sa retraite, enfin, à l’Université Paris 8.

S'il n'a pas cessé de faire référence à Marx, d'une façon d'ailleurs parfois très critique, il considérait, au rebours de certains courants marxistes dominants, et notamment d'Althusser, la déhistoricisation comme une erreur capitale. Il fut très lu en 1968 et dans les années suivantes ; son influence fut certaine sur de nombreux penseurs : il était par exemple admiré de Guy Debord, qui le citait fréquemment.

Ses principaux ouvrages furent d'abord, après La fausse conscience, parue aux Éditions de Minuit, et qui doit être prochainement rééditée, Sociologie de l'aliénation (PUF, 1971) ; Idéologies I et II (Anthropos, 1974 et 1978). Ces trois ouvrages sont une série d'applications de ses idées sur la conscience réifiée, les fausses identifications, la causalité « pré-dialectique », à des questions très variées, qui embrassent aussi bien une réflexion sur les œuvres de Swift et de Kafka que le totalitarisme, le maccarthysme, la sociologie de la connaissance, la «sociologie religieuse » de Max Weber. Idéologies II porte un sous-titre significatif : Althussérisme et stalinisme. Dans Études dialectiques (Méridien-Klincksieck, 1990), il constate : «Le marxisme est peut-être moribond, mais la dialectique se porte, en revanche, comme un charme » et il critique la conscience bureaucratique, cherche à définir l'Utopie et envisage un cas clinique de «logique réifiée ". Chez le même éditeur, il faut citer aussi, parus tous deux en 1987, Mannheim et le marxisme hongrois et Réflexions sur l'avenir des Juifs (également aux Éditions Méridien-Klincksieck) Le premier de ces ouvrages s'intéresse particulièrement aux questions du "phénomène idéologique » dans ses rapports avec l'Utopie ; dans le second, il envisageait le sionisme en tant que mouvement de libération nationale dénoncé par un " antisémitisme de gauche » inavoué, procédant par « fausses identifications » et manifestant le succès d'une idéologisation manichéiste et dédialectisante. Joseph Gabel donna par la suite de nombreuses conférences sur ce thème, mais, dès la parution du livre, il se montrait bon prophète en écrivant, à propos du maniement pervers et idéologisé des concepts de racisme et d'anti-racisme, dans son avant-propos : " Nous assisterons peut-être une fois à des pogromes anti-racistes ».

D'autres ouvrages furent publiés directement en anglais, en allemand... Il dirigea, assisté de Bernard Rousset et Trinh Van Thao, plusieurs ouvrages collectifs, L'aliénation aujourd'hui, La mort aujourd'hui, Actualité de la dialectique (Anthropos, respectivement en 1974, 1976 et 1980) et fut un collabarateur de L'Encyclopédia Universalis et de plusieurs revues, notamment L'homme et la société, dont il était membre du comité de direction.

Joseph Gabel croyait en l'intelligence et en l'homme ; il était ouvert à de nombreux savoirs, et notamment s'intéressait aux apports de la psychanalyse. L'axe principal de sa réflexion a consisté en la recherche des causes de la renonciation à la raison, des masques que prend cette renonciation, et dans l'étude des catastrophes qu'elle entraîne. Cette recherche s'appuyait sur l'immense culture de cet auteur qui était à la fois sociologue et historien, et dont le nom figure aussi bien, entre autres, dans le Dictionnaire des Philosophes que dans le recueil de textes La psychiatrie, publié par Jacques Postel, dans le Biographical Dictionary of Neo-Marxism que dans les Contemporary Authors. C'était un homme d'une grande intelligence et d'un subtil humour, parfois caustique et néanmoins très tolérant. Son œuvre restera comme celle d'un esprit doué de lucidité dans le regard qu'il a porté sur son époque et de courage dans ce qu'il en a écrit. Tous ceux qui l'ont connu de près savaient qu'ils étaient en présence d'un homme remarquable.

Georges Gachnochi 